\title{
10 health stories that mattered: Jan. 10-16
}

- Health Canada has delayed its decision on whether to approve the abortion pill mifepristone (RU-486) until the fall after requesting more information from the drug's manufacturer. Approval decisions about pharmaceuticals typically take about nine months, but Health Canada received the mifepristone application in December 2012.

- The smoking-cessation drug Champix (varenicline) "is suspected of playing a major role" in 44 deaths, including 30 suicides, according to an investigation by the Vancouver Sun based on adverse reaction reports in a Health Canada database. In a statement to the Sun, the drug's manufacturer, Pfizer, said there was "no reliable scientific evidence to demonstrate that Champix causes serious neuro-psychiatric events."

- The Public Service Alliance of Canada wants the federal government to adopt national standards to improve the mental health of its workforce and reduce the number of mental health disability claims, which account for nearly half of all disability claims among unionized civil servants. The union stressed the importance of a "psychologically healthy" workplace and urged the government to help identify the factors contributing to high levels of depression and anxiety in the public service.

- It has been a severe flu season in Canada and the United States and public health officials suggest there is no sign of it abating. The predominant strain of influenza this year, H3N2, wasn't included in the current flu vaccine and is more potent than many other strains, posing greater risks to children and seniors in particular.

- Canada will deploy a third mobile laboratory to Sierra Leone to assist Médecins Sans Frontières in testing samples from patients with Ebola. When the team arrives on Jan. 18, it will bring the number of Public Health Agency of Canada scientists in the country to six.

- Cyclotrons are now capable of producing enough medical isotopes to avert a shortage and replace those produced by aging nuclear reactors, according to researchers from the University of British Columbia. This potential solution will also solve problems associated with nuclear isotope production, such as high maintenance costs and radioactive waste disposal.

- The Ontario Medical Association rejected the provincial government's latest offer saying it will fund fewer than half the required new doctors. Meanwhile, the Ontario Association of Cardiologists is raising money for a possible challenge against the provincial government if cardiology billing fees are reduced, according to an email obtained by The Globe and Mail.

- Newfoundland and Labrador is attempting to "identify clear actions" on how to improve its costly health care system, Premier Paul Davis said at a summit on health care. The province spends more per person than any other province on health services, which consume $40 \%$ of its budget.

- Nova Scotia is considering using GPS tracking devices on patients at the East Coast Forensic Hospital, which serves people in the judicial system. In 2014, at least 40 patients at the facility went "absent without leave."

- Nearly 10000 employees of Alberta Health Services, about $10 \%$ of its workforce, earn $\$ 100000$ or more. Most are front-line employees who often work overtime, such as nurses, who account for a third of the higherearners. - Roger Collier, CMAJ

CMAJ 2015. DOI:10.1503/cmaj.109-4978 